\title{
¿Se puede hablar de solidaridad y defensa en la narrativa de Guaman Poma sobre los indios en "Buen gobierno"?
}

Can One Speak of Solidarity and Apology in Guaman Poma's Narrative about the Indians in the "Good government"?

\section{Mónica Morales}

University of Arizona, Arizona, Estados Unidos

Contacto: Morales7@email.arizona.edu

https://orcid.org/0000-0001-9164-217X

\section{Resumen}

En su lucha discursiva para lograr la justicia social, Guaman Poma habló de la población indígena del Nuevo Mundo e informó al rey acerca del impacto de la colonización en las sociedades andinas. ¿Cómo podía lograr este autor que el rey adquiriera una clara conciencia de las realidades que describía? Este ensayo reflexiona sobre el problema de la representación con el fin de exhibir de qué manera procesos de otrificación fueron primordiales para los objetivos políticos y éticos de Guaman Poma. En este contexto, discursos de la subalternidad y de derechos humanos convergen en una discusión que subraya los problemas de los mismos discursos y su validez. Este ensayo propone que hay reflexiones pendientes de estudio sobre producción intelectual, justicia y políticas de identidad que se relacionan en la representación del hombre andino que se manifiesta en la obra de Guaman Poma.

Palabras claves: Felipe Guaman Poma de Ayala; Solidaridad; Derechos humanos; Representación; Exclusión

\begin{abstract}
In the middle of discursive struggles, Guaman Poma spoke about the Indigenous people of the New World and informed the king about the impact of colonization in the Andes. ¿What could this author do to transmit to the king an accurate representation of what he described? This essay reflects on the problems of representation when dealing with "others", a crucial issue for Guaman Poma's political and ethical goals. In this context, discourses of subalternity and human rights converged in a discussion about the issues of such discourses and their validity. This article suggests that there are areas pending of study about the intellectual production, justice and identity politics that are activated when Guaman Poma builds representation of Andean people.
\end{abstract}

Keywords: Felipe Guaman Poma de Ayala; Solidarity; Human rights; Representation; Exclusion

Recibido: 02.09.19

Aceptado: 09.11.19 
Es imposible concebir el problema de los derechos humanos en el caso de los pueblos indígenas en América Latina sin considerar la premisa de que estos son un efecto del discurso colonial. Tómese por ejemplo la Constitución de Brasil (1988) o la de Bolivia (2009) al respecto, e inclusive la Declaración de Derechos Humanos Indígenas redactada por las Naciones Unidas $(2007)^{1}$. Del análisis del discurso de reconocimiento que estos documentos producen se desprenden representaciones de lo indígena que continúan circulando como parte de "formaciones" coloniales y dejan sus huellas en el presente, en el sentido que Ann Laura Stoler (2008) concede al término. El discurso de derechos está íntimamente ligado a la asimetría del poder cuyo centro epistémico más característico es el mundo colonial. Como Anthony Pagden (2003) bien lo formula, los derechos humanos se desarrollaron en el contexto de "prácticas legislativas y han permanecido estrechamente conectados con la expansión imperialista y sus consecuencias" (p. 173)2. En "Felipe Guaman Poma de Ayala: An Andean View of the Peruvian Viceroyalty, 1565-1615", una intervención importante en el foro crítico sobre la historia de los vencidos, Rolena Adorno trajo a discusión la unidireccionalidad de la representación. Adorno (1978) afirma que el colonizador produjo gran cantidad de material escrito sobre el mundo andino y el imperio inca. Si bien los indígenas formaban parte de estas narrativas como informantes anónimos y como objetos del relato, sus perspectivas sobre los eventos no se conocían (p. 121) $)^{3}$. Aunque las opiniones de Guaman Poma sobre la conquista y la colonización se hicieron públicas entre los años 1570 y 1615, argumento que el problema de exclusión que afectaba la narración de su historia, punto que resalta Adorno (1978) en su artículo (p. 121), persistió en otros aspectos. Esta dificultad va más allá del dilema de quién produce la representación, para destacar la cuestión ética y estética que se debe interrogar cuando se da voz e intercede por el otro en cuestiones de justicia social y en discursos comprometidos con los derechos humanos para el bienestar de los otros.

Tomando como base la defensa que Guaman Poma hizo de los derechos de los indígenas en la sección dedicada a los "Indios" en la segunda parte de su crónica, "Buen gobierno" (pp. 764-850)4, este ensayo problematiza la 
cuestión de quién realmente puede ejercer esta facultad de representar a otros y las limitaciones que esta capacidad lleva consigo. Para este propósito es necesario analizar la formación de los habitantes de los Andes como sujetos coloniales específicos, una transformación de esta población en indios y letrados principalmente. La lectura del artículo de Adorno a partir de la identificación que establece entre Guaman Poma y la alfabetización es central al argumento de este ensayo para destacar aspectos no analizados por la crítica que ha generado el texto hasta el momento ${ }^{5}$. La cuestión del privilegio para representar a otros y la de la solidaridad asociadas con el papel del intelectual en el proceso solo se pueden apreciar considerando este nexo identitario. Para este fin pongo las continuas referencias al texto que lo clasifican como iniciativa solidaria, por parte de Adorno, en conversación con la crítica poscolonial y subalterna, donde esta noción de benevolencia es esencial para desmantelar la circulación ideológica en diversos niveles de articulación de derechos a bienestar. Entre estos se destacan la exclusión de todo ideal de subjetividad no europeo y la separación del indígena de la capacidad intelectual, así como la de la facultad lingüística del habla, de la actividad crítica y confrontación que conducen a lo político.

¿Quién tiene derecho a representar a otros en la realidad histórica que reconstruye la sección de "Buen gobierno"? Adorno (1978) proporciona un ejemplo bastante ilustrativo de esta interrogante en el contexto donde Guaman Poma propone el mejoramiento de las instituciones coloniales (encomienda y corregimiento), así como de la evangelización y prácticas inquisitoriales de la Iglesia colonial (p. 122). La situación que describe Adorno introduce al lector al informe que hace el cronista andino sobre los procedimientos inquisitoriales del sacerdote español Francisco de Ávila:

Guaman Poma narró sus propios viajes de pueblo en pueblo, durante los cuales entrevistaba tanto a la gente andina como española. Al narrar su conversación con tres ancianas de Hatunxauxa, escribió que ellas le informaron sobre las persecuciones y torturas a las que sometían a la población indígena bajo la dirección de Ávila para hacerlos confesar su idolatría. (1978, p. 136) 
En primera instancia se pudiera argumentar que la cita demuestra la intencionalidad de Guaman Poma de asegurar la posición de las ancianas como sujetos en control de su propia historia en un momento en que los españoles reimaginaban la historia andina en sus escritos ${ }^{6}$. Sin embargo, lo que resalta en esta cita es el deseo, tanto de Adorno como de Guaman Poma, de dar voz. El párrafo llama la atención a la solidaridad del intelectual y a la tecnología que hace posible circular las voces y experiencias subalternas en la historia. La respuesta ética y la alfabetización se vuelven los instrumentos que pueden plantear problemas, pedir reformas y concretizar una presencia en el escenario de la historia mediante la escritura. Adorno (1978) define esta actividad de Guaman Poma en términos de una nueva categoría social y agencial, "él creó para sí mismo, utilizando la escritura, un rol social que no estaba disponible para él en el mundo cotidiano externo" (p. 131). Al interpretar esta temprana ilustración de política de identidades coloniales que está enmarcada en la capacidad del sujeto de leer y escribir, y que Guaman Poma utiliza para intervenir socialmente, se deduce que la alfabetización comienza a mediar la defensa de derechos. El privilegio de Guaman Poma de desplegar socialmente su compromiso ético con el oprimido y la posibilidad que tiene este último para tener representación por parte de sujetos como Guaman Poma abre espacios de análisis para cuestionar el tipo de defensa que individuos posicionados en más de una cultura pueden generar?

"Buen gobierno" es el producto de la respuesta ética del letrado a los estragos producidos por la apropiación de tierras, la desposesión de los cuerpos indígenas de su energía laboral y la absorción y acumulación descontrolada de recursos. En tal sentido funcionaría como una defensa legítima de quien responde al llamado de los que experimentan abusos de poder en sus vidas. Adorno (2013) lo explica en los siguientes términos:

Guaman Poma entendía muy bien que [...] los colonizadores españoles venían para quedarse. Así que añadió a su relato de la historia andina precolombina y de la conquista española un tratado extenso sobre "buen gobierno", en el que se enfocaba en cómo hacer que la administración colonial fuera más receptiva a las necesidades de la gente de los Andes y a prevenir la ruina de la sociedad andina. (p. 177) 
En combinación con su comentario sobre el cambio de percepción que Guaman Poma experimenta con respecto a las campañas de extirpación (Adorno, 1978, pp. 134, 136); la expresión compasiva por la religión tradicional (Adorno, 1991, p. 242); y la urgente demanda por reformas que se puede observar en la totalidad de la sección dedicada al buen gobierno, se observa que la reflexión de Adorno trae una y otra vez a la superficie la cuestión del compromiso solidario de Guaman Poma con su momento histórico y la población indígena de los Andes ${ }^{8}$. Su actitud benevolente opera como una categoría que no solo nos hace pensar en el conflicto que produce el ignorar la representación como un problema moral, estético y político, de los cuales se encargan, entre otras disciplinas, los estudios poscoloniales y subalternos, sino que también abre un espacio para dialogar críticamente con la representación desde la perspectiva del discurso de derechos humanos en el presente. El bienestar social y material de la cultura indígena, junto con su proyección en el futuro y su relación con el Estado cristiano y sus políticas económicas y de reconocimiento son el motor que mueve la escritura de "Buen gobierno" y el compromiso que une a Guaman Poma con los debates y preocupaciones políticas actuales de la población indígena de todas las Américas y el planeta.

La posición de Gayatri Spivak $(1988$; 2004) con respecto a la complejidad política y estética de la representación se combina en el presente ensayo con el análisis del discurso de derechos humanos por medio de la idea de que todo entendimiento de la opresión no debe ignorar la respuesta solidaria del intelectual. Especialmente si se considera el elemento ideológico al que Walter Mignolo hace referencia al anclar históricamente el concepto de privilegio intelectual en el siglo XVI. Mignolo (2009) explica,

[...] ser y sentirse un individuo occidental y cristiano implicaba también tener "dominium" sobre la enunciación y asumir que aquello que fuese conceptualizado de acuerdo con principios y categorías de conocimiento greco-latino correspondía a la forma como el mundo era realmente. (p. 9)

En este contexto, la advertencia de Spivak (2004) con respecto a la necesidad de cuestionar la identidad de quién "distribuye" los derechos (pp. 523-524) se 
hace imperativa por lo siguiente. El dar voz al oprimido simboliza la ilusión de "transparencia" (Spivak, 1988, p. 275) que oculta la complicidad del intelectual con el poder, con la forma en que la representación da significado y "escenifica" la necesidad y al necesitado por medio de la escritura. Su versión de la experiencia no es más que la ejemplificación de la consideración no crítica de la dualidad de la representación como arte y proxy (Spivak, 1988, pp. 275-276). La circulación de la ideología se deriva de este proceso y se observa en la formación de sujetos (Spivak, 1988, p. 279), articulada por un intelectual que consolida otros intereses (Spivak, 1988, p. 275), como lo sugiere Mignolo (2007b): un individuo que ha sido alfabetizado y socializado en terreno epistémico imperial.

El objetivo del cuestionamiento sobre quién distribuye los derechos persigue revelar el hecho de que la educación occidental garantiza la idea de privilegio y compromiso. Spivak explica este problema en términos de "darwinismo social - el más apto debe asumir la carga de corregir los errores de los no aptos" (Spivak, 2004, p. 524). También, astutamente, agrega un punto que no detecta Mignolo,

[...] ser capaz de lograr subvención del Norte para un proyecto, es decir, entender y plantear el problema inteligible y persuasivamente para el gusto del Norte, constituye en sí una prueba de cierta discontinuidad epistémica con los pobres educados de manera deficiente. (Spivak, 2004, p. 527)

La solidaridad funciona en forma de privilegio que no solamente denota asimetría en la distribución de la educación y alfabetización — como bien lo representa el caso de las ancianas con respecto a Guaman Poma quien les da voz-, pero también trae consigo la idea de resaltar la discontinuidad con el centro epistémico dominante. Quien representa, genera ayuda o concede presencia en la historia, pero lo logra solo con base en un tipo de representación que mantiene esta clase de ruptura. En el intento de consolidarla, el intelectual construye diferencialmente a los sujetos que representa y por los cuales intercede a través de la escritura. El problema radica aquí en la formación de sujetos como productos de relaciones jerárquicas y de ideales normativos de subjetividad 
que disimuladamente circulan dominación mediante nociones de lo humano y discursos de reconocimiento que corresponden a otro centro epistemológico, como lo advierte Mignolo (2011). La noción de "indio" hace legible estas problemáticas que la solidaridad pone en marcha en el texto de "Buen gobierno".

\section{Sobre escenificaciones, educación y la capacidad lingüística}

De la compleja red de relaciones sociales y de producción que formaron el espacio colonial surgieron nuevas identidades. Obligaciones laborales, prácticas de extracción y estilos de vida articulados por lo económico y nociones occidentales que informaban la definición de lo que constituía "ser humano" produjeron nuevos roles sociales y entidades en el mundo andino. El concepto de "indio" se destaca en este proceso. Para Olivia Harris (1995), el concepto que Colón puso en circulación para referirse a la población del Nuevo Mundo se convirtió en una "categoría fiscal" en los Andes (p. 354). Ello quiere decir que la población indígena puede existir y ser visible solamente dentro del marco de inteligibilidad que proporcionan las condiciones de servicio laboral y ganancia, estipuladas por la corona, la Iglesia y la población de conquistadores españoles. Irene Silverblatt ubica este proceso de formación de subjetividades "en el corazón de la construcción del imperio español" (Harris, 1995, p. 279). Comenta que los españoles "predicaban ser indio con el fin de asegurarse sujetos indígenas leales" (1995, p. 279). Sin embargo, esta imposición tan violenta del término - y la subjetivización que trae consigo - suscitó la necesidad de declarar lo opuesto, es decir, de que uno no era español. Sabine MacCormack afirma que

\footnotetext{
[...] este reconocimiento tenía un resultado positivo de llegar a conceptualizar una idea de identidad que estaba ahora definida no solamente en función de las características loables que un Indio debería acoger, sino que también consistía en considerar las características “españolas" que debía rechazar. (2001, p. 201)
}

El discurso de derechos de Guaman Poma se conecta con este proceso de diferenciación. Cuestiona la idea de la superioridad moral española sobre la indígena y establece que los pobladores de los Andes eran verdaderos cristianos tanto por experiencia histórica como por conducta moral (pp. 843, 858, 876, 887, 
898). Investigar los esfuerzos de Guaman Poma para establecer desacuerdos y equilibrio de poder en los Andes implica considerar la forma en que las relaciones sociales del imperio inciden en la producción de indios por medio de la transformación de la población originaria de la región en indios o sujetos coloniales ${ }^{9}$. Su discurso sobre derechos no se mantiene al margen de este proceso de producción que es el resultado de la socialización imperial y de sus intereses. Este discurso no solamente articula al otro como diferencia, lo presenta como víctima, en el sentido cristiano de la palabra. Dicho sentido fue inaugurado por los "Pobres de Jesucristo", disimulando la circulación ideológica en la pluma de quien distribuye la defensa de derechos. La siguiente cita de la crónica de Guaman Poma ilustra este punto:

Y ancí trayendo autoridad no se llegauan los pobres ne querían hazer daño a los pobres en mi presencia, como se haze cienpre. Como no me conosen y me uen pobre, en mi presencia, quita sus haciendas y mugeres y hijas con poco temor de Dios y de la justicia. Digo cierto, contando de mi pobresa, metiéndome como pobre entre tantos animales que come pobres, me comía tanbién a mí como a ellos.

Para dar fe desto, conbenía escriuir como sentenciador de ojos y a uista como cómo se a prociguido primero de mí. Que para ello me hize pobre, metiéndome en los demás pobres, que ací conbenía para este efeto, de cómo se saue que al pobre menosprecia los rricos y los soberbiosos sobre ellos, paraciéndole que adonde está el pobre no está aý Dios y la justicia. Pues a de sauerse claramente con la fe que adonde está el pobre está el mismo Jesucristo; adonde está Dios, está la justicia.

Y ancí, cristianos, no le menosprecies a los pobres de Jesucristo porque ueáys cómo lo preciguís a los pobrecillos. Y para que conste la uerdad, contaré la pobresa que paso en mi persona y trauajos y desuenturas.

¿Qué me hará de los yndios pucilánimos, encapases, tontos, cin juycio, que los españoles son rrobadores de sus haziendas y de sus pueblos y términos y, fuera desto, de sus pociciones y de sus mugeres y hijos y hijas que le dio Dios y se hallan apurados, cargándole como a caballo? Por otra parte le haze esclabo; adonde le llama tributario es claramente decille esclabo. Y ací no mulitplica ni puede multiplicar y esta carga se le carga que no le defiende el Ynga. (pp. 903-904)

El gesto de benevolencia que el párrafo anterior ilustra pone de manifiesto la construcción de la subjetividad del indio. De esta producción y formación 
de identidades por medio del discurso cristiano y la escritura se observan tres aspectos que demandan análisis.

\section{Los Pobres de Jesucristo}

El primero apunta a aquello a lo que solo se puede tener acceso a través del conocimiento. Lo que llama la atención entonces es la complicidad de la alfabetización con el privilegio de enunciar el pensamiento cristiano y sus subjetividades normativas. Si el párrafo hace referencia a la solidaridad de Guaman Poma con el necesitado, también plantea sin problema que la condición "precaria"10 que la escritura denuncia y circula solo puede ser entendible y moralmente efectiva si la situación se escenifica. Este efecto positivo se logra si el indígena aparece articulado discursivamente por la pobreza. En tal sentido, la cita se apega al amplio y aceptado principio cristiano que postula el imperativo de socorrer a los pobres económica y socialmente (Beed \& Beed, 2010, p. 13). Este principio, que se origina en la injusticia económica y es sintomático del "desplazamiento humano de un diseño superior," como el representado por el escenario del Jardín del Edén antes de la Caída, se caracteriza por promover cooperación, armonía e igualdad entre los seres humanos (von Rad, citado por Beed \& Beed, 2010, p. 16). Guaman Poma se solidariza y se identifica totalmente con este principio y la condición de pobreza que se deriva de él, según lo describe la cita, para ofrecer evidencia de testigo presencial ante el desplazamiento que su cultura experimenta hacia la desposesión de bienestar absoluto.

En el pensamiento cristiano, el cuidado de los pobres es un imperativo, no una opción, porque Dios, que está del lado de los pobres, los débiles y los oprimidos, desea que su gente luche contra la desigualdad económica (Beed \& Beed, 2010, p. 16). Guaman Poma constituye al indio como el Pobre de Jesucristo en necesidad de ser representado por un sujeto cristiano, así como protegido y salvado de los propios cristianos. A pesar de ello, la cita demuestra el papel que la representación tiene en crear la escena de la opresión de tal manera que disfraza la necesidad de agentes de poder que puedan hablar por los indios. No es casualidad que Guaman Poma sea uno más de estos pobres y nos informe que ya no está 
el inca para ver por los indios tampoco, lo que recuerda al lector la condición legal del indígena como entidad infantil. Legalmente, los indios eran vistos como niños que teóricamente poseían derechos, pero no podían ejercerlos hasta edad razonable. El filósofo y teólogo dominico Domingo de Soto (1494-1560), explica que estos poseían dominium, derecho a propiedad, "a cualquier cosa, para usarla a [su] beneficio por cualquier medio, siempre que la ley lo permitiera" (en Pagden, 1990, p. 17). Sin embargo, dominium se reconocía con relación a los derechos de los niños que, si bien lo poseían, estaban sujetos a la autoridad de sus guardianes y padres a la hora de ejercerlos. La solidaridad de Guaman Poma disfraza la circulación de esta ideología y su asentamiento en los Andes, donde si ya no se pueblan las páginas de la historia con bárbaros, caníbales, ni borrachos ${ }^{11}$, se ocupan con víctimas, entidades legales infantiles dependientes y pobres. De su defensa, articulada como sermón, se desprende el hecho de que solo hay una subjetividad normativa ideal que califica para recibir derechos. Esta corresponde a la identidad europea cristiana que los Pobres de Jesucristo representan en la cita sobre el Nuevo Mundo.

\section{El indio como entidad incapacitada}

El análisis de los aspectos estéticos, éticos y políticos de la representación nos ayuda a entender de qué manera la cita de Guaman Poma también pone de manifiesto que el cuidado y ayuda por la causa de derechos indígenas quedaba supeditado a la necesidad de establecer discontinuidad epistémica entre grupos. Aquí se introduce el segundo punto. El párrafo demuestra la puesta en escena del indígena como entidad intelectualmente incapacitada, como idiota e irracional, e inclusive cobarde (p. 846). El problema de discontinuidad se concretiza históricamente con las prácticas educativas de la colonización y la conversión. Estos sistemas promovían una educación que confina al indio a obediencia absoluta, a subordinación. Al respecto, Adorno (2000 [1986]), explica cómo los indios ladinos, es decir, "alguien que era supuestamente capaz de expresarse en castellano, cristiano en creencia, e hispanizado en costumbre" (p. xliv), eran “detestados por los colonos y [...] a menudo exiliados de sus provincias por 
el miedo a que presentaran demandas judiciales en contra de éstos" (Adorno, 1978, p. 131). Aunque la alfabetización no era bienvenida porque se podía poner al servicio de contrarrestar la corrupción colonial, Guaman Poma promovía la implementación de clases para que la gente indígena aprendiera a leer y a escribir. Lo que se prefería era el catecismo. Esta rama del conocimiento y aprendizaje religioso promovía obediencia y continuidad epistémica parcial. Contraria a la alfabetización, facilitaba capacidades destinadas a implementar la identificación del indio con la subordinación y vulnerabilidad. La siguiente descripción que Guaman Poma presenta en "Buen gobierno" ilustra este problema:

Que Jesucristo esté en mi boca, en mi lengua, en todas mis palabras, Cruz.

Que Jesucristo esté mi corazón, en mi alma, en todos mis pensamientos y todas mis obras. Cruz.

Que Jesucristo me guarde por delante y detrás. Cruz. Que me proteja de los demonios enemigos, que me proteja de los hombres malos [...]

Que me proteja de la muerte repentina, que pueda confesarme y hacer mi testamento $[\ldots]$

Que Jesucristo me proteja de las serpientes, del amaru, las víboras, los $u r u$, perros que comen y muerden a los hombres, del fuego, del agua, del rayo y el oro. Cruz.

Jesucristo guárdame de las injusticias, del corregidor, alguacil, alcalde, pesquisidor, jueces, visitadores, padre doctrinante, de todos los españoles, los ladrones, los despojadores de hombres. Protégeme. Cruz. [...]

Jesucristo, protégeme del mala lengua, de hombres y mujeres borrachines, borrachos, locos, enajenados, de los que no temen a Dios ni a la justicia, Protégeme. Cruz.

Jesucristo, protégeme este día y esta noche de todas las malas tentaciones y de todos los hombres malos. Protégeme. Cruz. (p. 837)

El autor muestra en esta cita la forma en que la enseñanza religiosa opera y configura sujetos coloniales. La humanidad indígena no se concibe fuera de un sistema jerárquico análogo al imperio, organizado sobre la base de la dependencia y el miedo. Como se lee en la cita anterior, la subjetividad indígena ideal califica para existencia solo dentro del espacio determinado por la ansiedad, 
la incompetencia intelectual y el silencio. Estas categorías de identificación impuestas o normas, de acuerdo con críticos como Judith Butler, representan el factor ideológico clave a considerar para entender cómo se constituyen los sujetos/indios y el papel que juega en ello la identificación con la ley ${ }^{12}$. Guaman Poma demuestra la forma en que las normas hacen visible al indio dentro del marco de inteligibilidad que refleja exclusivamente los intereses coloniales.

Memorización, repetición, subordinación, vulnerabilidad y temor constituían las principales habilidades y aptitudes mentales que la instrucción religiosa perseguía inculcar en la población indígena (pp. 826, 828, 832837). Este tipo de enseñanza promovía la importancia de vivir bajo constante protección (pp. 834-836), pero no ayudaba en nada a erradicar al indígena de la opresión que el pasaje en consideración ilustra. La cita más bien conecta a la gente no cristiana con las formas de experiencia más atemorizadoras producidas por acciones humanas específicas o fenómenos naturales. Lo jerárquico y el rechazo del colonizador por los indios ladinos y alfabetizados que combaten el abuso del poder indican la brecha epistémica entre el indígena y quienes los representan, organizan las relaciones de producción y distribuyen derechos a condiciones de vida aceptables y dignas. En ninguna parte se puede apreciar mejor esta instancia de discontinuidad epistémica más que en la representación que Guaman Poma hace de los indios repitiendo normas y principios cristianos: "Que Jesucristo esté en mi boca, en mi lengua, en todas mis palabras. Cruz. [...] en todos mis pensamientos y todas mis obras" (p. 837); "Protégeme en esta tierra [...] Perdóname a mi padre, mi madre" (p. 832). Este conjunto de reglas y deseos aparta al indígena de la capacidad de actuar por sí mismo y anula toda posibilidad de identificaciones que no coincidan con la incapacidad y vulnerabilidad que predica la ideología dominante. Este aspecto es un punto importante a considerar ya que el catecismo y sus enseñanzas eran parte de la vida diaria de los indígenas y como tal consolidaban disfrazadamente intereses imperiales e imperativos de subordinación en todas las dimensiones de la existencia. El acto de repetición, por lo tanto, vendría a simbolizar el ceder, por parte del indígena, su derecho a verbalizar críticamente su propio recuento de lo que considera injusto, en el caso 
planteado por el catecismo y su rol como formador de indios, sujetos leales y sumisos políticamente. En tal sentido, las enseñanzas religiosas le roban la voz. Separan el habla indígena de la instrumentalidad política, de la capacidad y el medio para embarcarse en la expresión de desacuerdo y disputa.

\section{Habla indígena e instrumentalidad política}

Para considerar esta idea, que constituye el tercer punto, es necesario referirnos a Jacques Rancière, para quien la política implica una actividad que conduce a una reconfiguración del orden imperante mediante un cambio en la distribución de los cuerpos con respecto a un sitial adonde antes no pertenecían. Tal actividad introduce una noción heterogénea al orden cuya utilidad es hacer visible y audible aquello que no era perceptible, así como también ilustrar la contingencia de este orden y la igualdad de todos en la capacidad lingüística (1999, p. 30). La reflexión de Rancière es útil para pensar en las relaciones que resultan del uso que se le da al habla en el contexto que Guaman Poma desarrolla en "Buen gobierno". Si su actividad crítica en contra del sistema colonial lo ubica en el grupo de quienes pueden ofrecer remedio a los problemas de distribución desigual de recursos y derechos, su tratamiento del habla cuando se refiere al indígena de las citas no lo ilustra en relación con su capacidad de declaración asertiva de sus propios intereses. Por el contrario, lo lingüístico no muestra ruptura ni confrontación, sino subordinación e incapacidad. Ilustra más bien la formación de sujetos que actúan en nombre del interés ideológico imperial. Al ser violentamente impuestos identificaciones con normas transatlánticas — valores, principios y formas de ser, la gente indígena se encontró obligada, como los pasajes analizados lo testifican, a concebir su bienestar y personas a partir de otro lenguaje y por ende, ideología. El dar atención al contexto en el cual ocurre el habla indígena nos informa sobre la discontinuidad entre habla y cambio de posición. Los indios ladinos y los indígenas alfabetizados dispuestos a contrarrestar el exceso de poder y presentar su desacuerdo no tienen acogida en la sociedad descrita por Guaman Poma.

En el caso personal del autor, se podría argumentar que este transfiere a la escritura el espacio de confrontación en el que yace lo político. Entra al espacio 
de enunciación a través del género autoetnográfico (Pratt, 2008 [1992], p. 7). Así, en la sección de la entrevista con el monarca, "Capítulo de la pregunta", se observa desacuerdo con la distribución desigual de poder en las decisiones sobre la administración de recursos y bienestar del mundo andino. Allí el cronista incita al rey Felipe III a implementar reformas protectoras de la vida indígena. La misma actitud se observa en el capítulo de los indios con su crítica al Estado (pp. $845,851,857,864,866-867,869,872-879)$. Simultáneamente y sin embargo, su discurso por los derechos indígenas ejemplifica más que nada la asimetría de la representación, la “contaminación” del acto, como diría Drucilla Cornell (2010) al cuestionar el derecho del letrado a representar al otro: "[s]i el sujeto que representa se encuentra en la posición del privilegio que se le niega al otro, la representación que resulta siempre estará contaminada por el mismo privilegio" (p. 104).

Como sujeto posicionado en más de una cultura, solidaridad y privilegio le permiten a Guaman Poma dar voz al mundo indígena, basándose en una red de conocimiento de la cual definiciones de lo que significa ser humano emergen con valor universal y estrechamente conectadas a principios "religiosos y epistemológicos" (Mignolo, 2009, p. 9), y a las consecuencias imperiales de la expansión (Pagden, 2003, p. 173). De esta manera, su discurso se compromete con la defensa de una subjetividad normativa de inescapable origen europeo, establecida por las narrativas fundacionales del expansionismo y sus autoridades coloniales y religiosas. Como bien lo explica Pagden (2003) con relación a la genealogía occidental del concepto de "derechos humanos", "[su] historia [...] nos recuerda que si deseamos declarar cualquier creencia en lo universal tenemos que comenzar por afirmar nuestra disposición a asumir, y a defender, por lo menos algunos de los

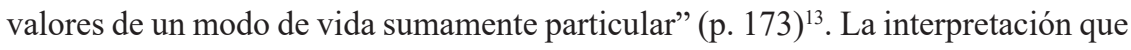
Guaman Poma hace de su historia desde el punto de vista del Génesis, la correlación que establece entre las costumbres y las nociones del bien común de los primeros habitantes de los Andes con las de los cristianos y la civilización occidental (pp. 842, 858, 876, 887), su discurso antiesclavitud (pp. 887-889), y su distribución de los Andes y América dentro del orden espacial global de la cristiandad e imperio - que los Andes apoyan económicamente (pp. 888-889) - ilustran la perspectiva local y 
particular que Pagden identifica en el discurso de derechos humanos. El discurso de derechos de Guaman Poma no se aleja de esta tendencia, lo que problematiza su defensa y representación de lo indígena.

\section{Comentarios finales}

A través de la solidaridad del intelectual que en la subjetividad letrada de Guaman Poma se sugiere pero no se analiza, se abren dos espacios importantes, el ideológico y el político, para interrogar la representación en relación con lo que la autoriza. La sección sobre los indios en la parte de "Buen gobierno" ejemplifica este aspecto con la respuesta ética. La solidaridad se entiende como punto de partida analítico para desenmascarar el imperativo ideológico que impide una lectura transparente de la defensa del indígena. También se entiende como lo que separa su capacidad lingüística de la confrontación que constituye lo político. En el proceso de dar voz al oprimido, la alfabetización y su enunciación ideológica encuentran apoyo y vía de circulación en la solidaridad del autor. Sus citas al respecto son valiosas, pues nos enfrentan con lo que ocurre cuando los sujetos coloniales que habitan más de una cultura se vuelven el objeto de la compasión humana del intelectual y se comprometen con el derecho a dar voz a quienes no la tienen. Lo relevante de un análisis bajo la perspectiva de la benevolencia es que nos permite visualizar concretamente la constante circulación de la ideología en poder, en tiempo y espacio. La escenificación de la existencia precaria de los indios como los Pobres de Jesucristo constituye un ejemplo, como la discusión en este ensayo lo demuestra. Este pone de manifiesto el problema de la formación de sujetos coloniales, a quienes la normativa de la pobreza les concede existencia histórica y la posibilidad de convertirse en objetos de reforma. No obstante, la defensa del indígena por medio de la escritura disfraza y no interrumpe el dominio ideológico que se acentúa más aún cuando Guaman Poma informa lo que los indios hablan.

"Buen gobierno" constituye un enfoque crítico no solo de las condiciones materiales de la vida de los indios después del año 1532, sino también de la formación de sus capacidades intelectuales. El problema de la alfabetización 
versus la enseñanza religiosa por medio del catecismo surge como punto de análisis del tema cuando la solidaridad de Guaman Poma intelectual se cuestiona. $\mathrm{Su}$ benevolencia no se aparta de los modelos identitarios normativos de la Cristiandad. La producción de sujetos cristianos implica un ejercicio intelectual no crítico, facilitado por la repetición y la asimilación de normas que confieren existencia exclusivamente bajo comportamientos ilustrativos de sumisión, vulnerabilidad y desposesión. Ser indio no alfabetizado, pero socializado en el catecismo imperial, significa vivir en necesidad material y en reiterativa demanda de salvación, protección y representación. Esta dinámica ilustra la separación epistémica entre grupos, dominador y dominado, a través de la cual la formación de sujetos ideales coloniales, practicada por la administración, la religión católica y el propio Guaman Poma, se complementan en las escenas de la escritura. La separación del habla de los indios del razonamiento crítico y de la actividad política es una consecuencia del discurso de defensa de sus derechos. Tal defensa pone al descubierto que la capacidad lingüística bajo la cual la igualdad de los seres hablantes se establece no articula confrontación, sino más bien subordina el cuerpo indígena y su capacidad de expresión lingüística a modelos y normas de humanidad foráneos. La problemática de la solidaridad vista desde esta perspectiva conecta la defensa de los derechos indígenas que Guaman Poma termina en el siglo diecisiete con los discursos de reconocimiento indígena contemporáneos. Como apunto al comienzo de este ensayo, la solidaridad es una de las tantas formaciones coloniales que constantemente está dejando huellas en el presente indígena.

\section{Notas}

1 Estos documentos pueden ser consultados en internet. La Constitución de Bolivia se halla en www.constituteproject.org/constitution/Bolivia_2009.pdf. Las secciones del Preámbulo y el Capítulo uno, artículo dos, entre otros, entregan información relacionada con el tema. En el caso de la Constitución de Brasil, véase la sección del Capítulo ocho dedicada a los indios, sus derechos y el Estado, www.wipo.int/edocs/ lexdocs/laws/es/br/br117es.pdf. La "Declaración de los Derechos Humanos Indígenas" redactada por las Naciones Unidas se encuentra aquí: https://www.un.org/esa/socdev/ unpfii/documents/DRIPS_en.pdf, consultar la página número dos. La referencia al pasado colonial determina el discurso de defensa de los derechos humanos. 
2 Todas las traducciones son mías a no ser que lo especifique.

3 Consultar Adorno (2000) y Ramírez (2005). Ramírez propone que el problema reside en que los primeros relatos y testimonios presenciales de la conquista son pocos y que la visión colectiva ha llegado a dominar el pensamiento histórico posterior.

4 Cito por número de página de la edición de Siglo XXI (Guaman Poma, 2006 [1615]).

5 La crítica sobre la narrativa de Guaman Poma reconstruye las bases intelectuales, literarias y artísticas occidentales del texto. Véase los trabajos de Adorno (1978; 1991; 2007; 2011; 2013), López-Baralt (1983), Pratt (2008 [1992]), Quispe-Agnoli (2006) y Zuidema (1994), para citar algunos. También se enfoca en las bases locales sobre las cuales Guaman Poma articula discursiva y gráficamente el origen de la cultura andina, explica su desarrollo e interacciones con el conquistador y su legado inca y occidental, para finalmente entregar soluciones prácticas pero destinadas al "fracaso" - como recientemente lo afirma Adorno (2011, p. 37)—. Véase la investigación de Brokaw (2002) que analiza el papel que juegan los sistemas de escritura andinos en estructurar el texto; también Vaccarella (2002), que investiga la presencia de África en los Andes; Mignolo (2007a) que propone la potencialidad del pensamiento del autor para consolidar iniciativas decoloniales; Urioste (1981) y Lienhard (1991) que exploran las interacciones del quechua y el español en el texto, así como las transgresiones discursivas que ofrece la escritura indígena. Esta documentación, a manera de sugerencia, no persigue ser exhaustiva para una obra que no cesa de generar investigación.

6 La Historia de los incas de Sarmiento (1943) ejemplifica y corresponde, de modo concreto y hasta extremo, a aquella tendencia.

7 Consultar la oportuna publicación de Journal of Commonwealth and Postcolonial Studies editada por Abraham Acosta (2018) y en particular, el ensayo de Olimpia Rosenthal. Rosenthal (2018) argumenta impecablemente la imposibilidad de concebir la historia crítica de Guaman Poma como un proyecto decolonial. Por ende, se puede argumentar que la cuestión de la solidaridad hace visible el peso ideológico occidental que Rosenthal observa en todo esfuerzo que el autor emprende por defender y asegurar presencia de lo local en lo futuro.

8 Véase también el estudio de Brading (1991).

9 Consultar la obra de Matienzo (1967 [1567]), Toledo (1986; 1989) y Durán (1982) sobre el catecismo de José de Acosta. Sus textos representan narrativas fundacionales de expansionismo y de remedio que ilustran la complicidad de la cristiandad (con los principios del Concilio de Trento) con el colonialismo en la producción de indios, sujetos cristianos/coloniales, mediante disciplina, temor y sumisión. Véase también la investigación de Castro-Klarén (2001) y Morales (2016 [2012], pp. 29-75).

10 Empleo el término "precariedad" siguiendo las ideas de Judith Butler, que la define pensando en una condición asignada, distribuida diferencialmente, que no califica a quien se le impone a recibir apoyo social ni económico y por ende, defensa para la vida y su desarrollo (2015, p. 33). La realidad a la que el término de precariedad se refiere no 
se diferencia de la del espacio colonial ni de las estructuras e ideas a través de las cuales los cuerpos coloniales se relacionan y ordenan. El ejemplo de la pobreza y la denuncia de la encomienda y otras relaciones de producción y desposeimiento lo comprueban.

11 Consultar el trabajo de Morales (2016 [2012]), quien establece el empleo de la borrachera como una herramienta ideológica en el discurso colonial para justificar la implementación de la civilización cristiana en el mundo andino, así como también articular una crítica del sistema colonial y defensa de la cultura de la región, precisamente por parte de Guaman Poma. La solidaridad del autor, que es fruto de las relaciones de dos mundos, se manifiesta en ambos sentidos cuando se refiere a la lectura crítica de su cultura a través de las variadas relaciones de la población indígena con la chicha, bebida fermentada de maíz. Sin embargo, y en manera semejante a Bartolomé de Las Casas, Guaman Poma no deja de circular la ideología dominante en su recuento de reformas, representaciones de su cultura e interrogantes sobre la superioridad moral de su grupo sobre el conquistador.

12 Concerniente a este punto, véase Butler (1993; 2015).

13 En referencia a este aspecto, consultar las ideas de Žižek (2011, p. 164).

\section{Referencias bibliográficas}

Acosta, A. (Ed.). (2018). Introduction: Unsettling Colonialities: Readings and Interrogations. Journal of Commonwealth and Postcolonial Studies, 6(1), 3-16.

Adorno, R. (1978). Felipe Guaman Poma de Ayala: An Andean View of the Peruvian Viceroyalty, 1565-1615. Journal de la Société des Americanistes, 65, 121-143. Recuperado de https://www.persee.fr/doc/ jsa_0037-9174_1978_num_65_1_2159

Adorno, R. (1991). Images of Indios Ladinos in Early Colonial Peru. En K. J. Andrien y R. Adorno (Eds.), Transatlantic Encounters.Europeans and Andeans in the Sixteenth Century (pp. 232-270). Berkeley: University of California Press.

Adorno, R. (2000 [1986]). Guaman Poma. Writing and Resistance in Colonial Peru. Austin: University of Texas.

Adorno, R. (2007). The Polemics of Possession in Spanish American Narrative. New Haven: Yale University Press. 
Adorno, R. (2011). Felipe Guaman Poma de Ayala y su texto-testigo del mundo colonial. En I. Rodríguez y J. Martínez (Eds.), Estudios transatlánticos postcoloniales II. Mito, archivo, disciplina: cartografias culturales (pp.19-39). Madrid: Anthropos.

Adorno, R. (2013). Felipe Guamán Poma de Ayala: Native Writer and Litigant in Early Colonial Peru. En K. J. Andrien (Ed.), The Human Tradition in Colonial Latin America (pp. 173-198). Plymouth: Rowman and Littlefield Publishers, Inc.

Beed, C. \& Beed, C. (2010). Assisting the Poor to Work: A Biblical Interpretation. Christian Scholar's Review, 40(1), 13-38.

Brading, D. A. (1991). The First America. The Spanish Monarchy. Creole Patriots and the Liberal State 1492-1867. Cambridge: Cambridge University Press.

Brokaw, G. (2002). Khipu Numeracy and Alphabetic Literacy in the Andes: Felipe Guaman Poma de Ayala's Nueva corónica y buen gobierno. Colonial Latin American Review, 11(2), 275-303. doi: 10.1080/1060916022000023387

Butler, J. (1993). Bodies that Matter. On the Discursive Limits of "Sex". Nueva York, Londres: Routledge.

Butler, J. (2015). Notes Toward a Performative Theory of Assembly. Cambridge: Harvard University Press.

Castro-Klarén, S. (2001). Historiography on the Ground: The Toledo Circle and Guaman Poma. En I. Rodríguez (Ed.). The Latin American Subaltern Studies Reader (pp. 143-171). Durham: Duke University Press.

Cornell, D. (2010). The Ethical Affirmation of Human Rights. Gayatri Spivak's Intervention. En R. C. Morris (Ed.), Can the Subaltern Speak? Reflections on the History of an Idea (pp. 100-114). Nueva York: Columbia University Press.

Durán, J. G. (1982). El catecismo del III Concilio Provincial de Lima y sus complementos pastorales (1584-1585). Buenos Aires: Facultad de Teología, Universidad Católica Argentina. 
Guaman Poma de Ayala, F. (2006 [1615]). Nueva corónica y buen gobierno. Madrid: Siglo XXI.

Harris, O. (1995). Ethnic Identity and Market Relations: Indians and Mestizos in the Andes. En B. Larson, O. Harris y E. Tandeter (Eds.), Ethnicity, Markets, and Migration in the Andes. At the Crossroads of History and Anthropology (pp. 351-390). Durham: Duke University Press.

Lienhard, M. (1991). La voz y su huella. Escritura y conflicto étnico-social en América Latina, 1492-1988. Hanover: Ediciones del Norte.

López-Baralt, M. (1983). La iconografía de vicios y virtudes en el arte de reinar de Guaman Poma de Ayala. Dispositio, 8(22-23), 101-122.

MacCormack, S. (2001). Comment. En A. Burguière y R. Grew (Eds.), The Construction of Minorities. Cases for Comparison across Time and Around the World (pp. 194-212). Ann Arbor: The University of Michigan.

Matienzo, Juan de. (1967 [1567]). Gobierno del Perú. París, Lima: Institut Français d'Études Andines.

Mignolo, W. (2007a). Delinking. Cultural Studies, 21(2-3), 449-514. doi: $10.1080 / 09502380601162647$

Mignolo, W. (2007b). El pensamiento decolonial: desprendimiento y apertura. Un manifiesto. En S. Castro-Gómez y R. Grosfoguel (Eds.), El giro decolonial. Reflexiones para una diversidad epistémica más allá del capitalismo global (pp. 25-46). Bogotá: Siglo del Hombre Editores.

Mignolo, W. (2009). Who Speaks for the "Human" in Human Rights?. Human Rights in Latin American and Iberian Cultures. Hispanic Issues Online, 5(1), 7- 24. Recuperado de http://hdl.handle.net/11299/182855

Mignolo, W. (2011). Crossing Gazes and the Silence of the "Indians": Theodor de Bry and Guamán Poma de Ayala. Journal of Medieval and Early Modern Studies, 41(1), 173-223. doi: 10.1215/10829636-2010-016

Morales, M. (2016 [2012]). Reading Inebriation in Early Colonial Peru. Nueva York: Routledge. 
Pagden, A. (1990). Dispossessing the Barbarian: Rights and Property in Spanish America. Spanish Imperialism and the Political Imagination. Studies in European and Spanish-American Social and Political Theory (pp. 1336). New Haven: Yale University Press.

Pagden, A. (2003). Human Rights, Natural Rights, and Europe's Imperial Legacy. Political Theory, 31(2), 171-199.

Pratt, M. L. (2008 [1992]). Introduction. En M. L. Pratt, Imperial Eyes. Travel Writing and Transculturation (pp. 1-12). Nueva York: Routledge.

Quispe-Agnoli, R. (2006). La fe andina en la escritura: Resistencia e identidad en la obra de Guamán Poma de Ayala. Lima: Fondo Editorial de la Universidad Nacional Mayor de San Marcos.

Ramírez, S. E. (2005). To Feed and Be Fed. The Cosmological Bases of Authority and Identity in the Andes. Palo Alto: Stanford University Press.

Ranciere, J. (1999). Disagreement: Politics and Philosophy. Miniápolis: University of Minnesota Press.

Rosenthal, O. (2018). Guaman Poma and the Genealogy of Decolonial Thought. Journal of Commonwealth and Postcolonial Studies, 6(1), 64-85.

Sarmiento de Gamboa, P. (1943). Historia de los incas. Buenos Aires: Emecé Editores.

Silverblatt, I. (1995). Becoming Indian in the Central Andes of SeventeenthCentury Peru. En G. Prakash (Ed.), Imperial Aftermath and Postcolonial Displacements (pp. 278-298). Princeton: Princeton University Press.

Spivak, G. (1988). Can the Subaltern Speak? En C. Nelson y L. Grossbert (Eds.), Marxism and the Interpretation of Culture (pp. 271-313). Urbana: University of Illinois Press.

Spivak, G. (2004). Righting Wrongs. The South Atlantic Quarterly, 103(2-3), 523-581.

Stoler, A. L. (2008). Imperial Debris. Reflections on Ruins and Ruination. Cultural Anthropology, 23(2), 191-219. doi: 10.1111/j.1548-1360.2008.00007.x 
Toledo, F. de (1986). Disposiciones gubernativas para el virreinato del Perú 1569-1574. Sevilla: Escuela de Estudios Hispanoamericanos de Sevilla.

Toledo, F. de (1989). Disposiciones gubernativas para el virreinato del Perú 1575-1580. Sevilla: Escuela de Estudios Hispanoamericanos de Sevilla.

Urioste, G. L. (1981). The Spanish and Quechua voices of Waman Puma. Review: Literature and Arts of the Americas, 15(28), 16-19. doi: 10.1080/08905768108594090

Vaccarella, E. (2002). Estrangeros, uellacos, santos y rreys: la representación de los negros en la obra de Felipe Guaman Poma de Ayala. Revista Iberoamericana, 68(198), 13-26. doi: 10.5195/reviberoamer.2002.5743

Žižek, S. (2011). Against Human Rights. En A. Singh Rathore y A. Cistelecan (Eds.), Wronging Rights? Philosophical Challenges for Human Rights (pp. 149-167). Nueva York: Routledge.

Zuidema, R. T. (1994). Guarnan Poma between the Arts of Europe and the Andes. Colonial Latin American Review, 3(1-2), 37-85. doi: 10.1080/10609169408569823 